\title{
Adubação verde como fonte de nitrogênio para a cultura da berinjela em sistema orgânico
}

\author{
Cristina Maria de Castro(1), Bruno José Rodrigues Alves(2), Dejair Lopes de Almeida(2) \\ e Raul de Lucena Duarte Ribeiro ${ }^{(3)}$
}

\begin{abstract}
(1)Universidade Federal Rural do Rio de Janeiro (UFRRJ), Inst. de Agronomia, Dep. de Solos, CEP 23890-000 Seropédica, RJ. E-mail: crismcastro2002@yahoo.com.br (2)Embrapa Agrobiologia, Caixa Postal 74.505, CEP 23851-970 Seropédica, RJ. E-mail: bruno@cnpab.embrapa.br, dejair@cnpab.embrapa.br (3)UFRRJ, Inst. de Agronomia, Dep. de Fitotecnia, CEP 23890-000 Seropédica, RJ. E-mail: raul@ufrrj.br
\end{abstract}

Resumo - O objetivo deste trabalho foi quantificar a fixação biológica de nitrogênio (FBN) por adubos verdes em pré-cultivo e consorciados com berinjela em sistema orgânico, a utilização do $\mathrm{N}$ pela berinjela, e o impacto da adubação verde na produtividade de berinjela e no balanço de $\mathrm{N}$ do solo. Parcelas com crotalária, milheto e vegetação espontânea foram estabelecidas antes do plantio da berinjela. Após 60 dias, a FBN respondia por 53\% do $\mathrm{N}$ da crotalária. Como grande porcentagem da vegetação espontânea correspondia a uma leguminosa, um total de $48 \mathrm{~kg}$ /ha de $\mathrm{N}$ acumulados nessas parcelas originaram-se da FBN. Os pré-cultivos foram roçados para o plantio direto da berinjela, exceto metade das parcelas com vegetação espontânea, que foi incorporada ao solo. Plantou-se a berinjela em consórcio com crotalária e caupi, e de forma "solteira". Aos 52 dias, as leguminosas foram cortadas e deixadas nas entrelinhas de berinjela. A FBN para as leguminosas consorciadas variou com os pré-cultivos, situando-se entre $20 \%$ e $90 \%$ do $\mathrm{N}$ acumulado na planta. Com a técnica de ${ }^{15} \mathrm{~N}$ constatou-se que a berinjela se beneficiou do $\mathrm{N}$ da adubação verde em pré-cultivo e consórcio. Embora sem efeito sobre a produtividade da berinjela, a FBN nas leguminosas foi suficiente para repor todo o $\mathrm{N}$ retirado do sistema através dos frutos.

Termos para indexação: Solanun melongena, Crotalaria juncea, Vigna unguiculata, consórcio, fixação biológica de nitrogênio.

\section{Green manuring as nitrogen source for eggplant under organic cropping system}

\begin{abstract}
The objective of this work was to quantify biological nitrogen fixation (BNF) for green manures precropped and intercropped with eggplant in an organic cropping system, the use of $\mathrm{N}$ from BNF by the eggplant crop, and the impact of green manuring on eggplant yield and soil $\mathrm{N}$ balance. Plots with sunnhemp, millet and spontaneous weeds were established before eggplant planting. After 60 days, 53\% of sunnhemp $\mathrm{N}$ came from BNF. Since a high percentage of the spontaneous weed plots has corresponded to a legume specie, a total of $48 \mathrm{~kg} \mathrm{~N} / \mathrm{ha}$ were derived from BNF. Green manure in pre-cropping was cut to planting eggplants under no-till, exception made to half of the plot under spontaneous weeds that was incorporated into the soil. The eggplant was either intercropped with sunnhemp and cowpea or cropped alone. At 52 days, the legumes were cut and left close to the eggplant. The BNF contribution to the legumes depended on the pre-cropped species and varied between $20 \%$ and $90 \%$. Using the ${ }^{15} \mathrm{~N}$ technique, it was verified that eggplants benefited from the $\mathrm{N}$ of the green manure in pre-cropping or intercropping. Although without effect on eggplant yield, the BNF in the legumes was enough to compensate for the exported $\mathrm{N}$ in the harvested fruits.
\end{abstract}

Index terms: Solanun melongena, Crotalaria juncea, Vigna unguiculata, intercropping, biological nitrogen fixation.

\section{Introdução}

A utilização de estercos é amplamente recomendada na produção de hortaliças, de forma a garantir melhor condicionamento do solo e adequada oferta de nutrientes, especialmente $\mathrm{N}$ (Almeida, 1991). Na cultura da berinjela, as doses recomendadas se situam entre $1 \mathrm{a}$ $2 \mathrm{~kg} /$ cova, equivalente a de 200 a $400 \mathrm{~kg} / \mathrm{ha}$ de N (Trani \& Raij, 1996; Filgueira, 2000).
Em sistemas de produção orgânicos não é permitida a adição de adubos químicos sintéticos de alta solubilidade, em que se enquadram os fertilizantes nitrogenados, e a utilização de estercos pode vir a ser limitada no futuro pela exigência da produção deste insumo sob manejo orgânico (Brasil, 1999). Além disso, o uso de estercos pode gerar dependência de fontes externas às propriedades, aumentando o custo de produção. Dessa forma, a utilização de insumos alternativos, como os adubos 
verdes, pode permitir uma diminuição das doses de esterco atualmente aplicadas e contribuir para repor as reservas de $\mathrm{N}$ do solo, retirado do sistema com a colheita.

Existem várias formas de utilização de leguminosas como fonte de $\mathrm{N}$ para o solo (Calegari, 2000). A mais comum é a sua utilização sob a forma de pré-cultivo, em que o adubo verde precede a cultura principal, que se beneficia posteriormente com a mineralização do nitrogênio. Porém, nas condições tropicais úmidas, essa prática tem limitações quanto ao fornecimento de $\mathrm{N}$ em virtude das altas temperaturas e excessiva umidade, que proporcionam uma mineralização acelerada dos resíduos (Séguy et al., 1997). Se a cultura sucessora não tem sua demanda sincronizada com a mineralização do $\mathrm{N}$ do adubo verde, perdas significativas podem ocorrer e tornar a prática ineficiente como alternativa de adubação (Calegari, 2000). A utilização do consórcio possibilita a pronta disponibilidade de $\mathrm{N}$ para a cultura principal no momento do corte da leguminosa. Neste caso, a cultura principal se beneficia do $\mathrm{N}_{2}$ fixado pela leguminosa, seja pela excreção direta de compostos nitrogenados e pela decomposição dos nódulos e raízes, ou mais intensamente pelo corte da parte aérea da leguminosa que irá se decompor e liberar nutrientes durante o desenvolvimento da cultura principal. Normalmente, as leguminosas contêm altos teores de $\mathrm{N}$ em seus tecidos no período de floração, o que significa uma contribuição acima de $150 \mathrm{~kg} / \mathrm{ha} /$ ano de $\mathrm{N}$, com um percentual de $60 \%$ a $80 \%$ do N proveniente da fixação biológica de nitrogênio (FBN) (Giller, 2001).

As técnicas que utilizam o isótopo ${ }^{15} \mathrm{~N}$ permitem não somente quantificar a FBN nas leguminosas mas também avaliar a utilização do $\mathrm{N}$ de seus resíduos pela cultura principal, e a utilização da técnica da abundância natural de ${ }^{15} \mathrm{~N}$ é uma das alternativas para dimensionar in situ esses processos (Hödtke et al., 1999).

O objetivo desse trabalho foi quantificar a FBN por adubos verdes em pré-cultivo e consorciados com berinjela em sistema orgânico, a sua utilização pela cultura da berinjela, e o impacto da adubação verde na produtividade de berinjela e no balanço de $\mathrm{N}$ do solo.

\section{Material e Métodos}

$\mathrm{O}$ estudo foi realizado entre os meses de março a novembro de 2001, na área do Sistema Integrado de Produção Agroecológica (SIPA), que ocupa uma extensão de 60 ha e situa-se na Embrapa Agrobiologia,
Município de Seropédica, RJ (latitude $22^{\circ} 45^{\prime} \mathrm{S}$, longitude $43^{\circ} 42^{\prime} \mathrm{W} ; 33 \mathrm{~m}$ de altitude). O solo é classificado como Argissolo Vermelho-Amarelo, e a análise química, feita antes da implantação do experimento, conforme Embrapa (1997), apresentou os seguintes resultados: $\mathrm{pH}$ (água), 6,3; $\mathrm{Al}, 0,0 \mathrm{cmol} / \mathrm{dm}^{3} ; \mathrm{Ca}, 3,3 \mathrm{cmol} / \mathrm{dm}^{3} ; \mathrm{Mg}, 1,5 \mathrm{cmol} / \mathrm{dm}^{3}$; $\mathrm{P}$ (Mehlich 1), $69 \mathrm{mg} / \mathrm{dm}^{3} ; \mathrm{K}, 95 \mathrm{mg} / \mathrm{dm}^{3}$; matéria orgânica, $12,4 \mathrm{~g} / \mathrm{kg}$ (Walkley-Black). A área destinada ao experimento estava sob manejo orgânico havia mais de 10 anos, com cultivo de hortaliças, sendo os estercos de curral e de granja as principais fontes de $\mathrm{N}$ para as plantas.

Foram estabelecidos 12 tratamentos para a cultura da berinjela (Solanum melongena), híbrido F-100, em delineamento de blocos ao acaso com três repetições, dentro do esquema fatorial $4 \times 3$. Um dos fatores correspondeu à forma de plantio da berinjela/tipo de adubo verde usado em pré-cultivo, constituído de quatro níveis: Crotalaria juncea (crotalária), roçada, com plantio direto da berinjela; Pennisetum glaucum (milheto BRS 1501), roçado, com plantio direto da berinjela; vegetação espontânea, roçada, com plantio direto da berinjela; e vegetação espontânea, incorporada com enxada rotativa, com plantio da berinjela (aqui denominado plantio convencional). O segundo fator foi a forma de cultivo da berinjela, constituído de três níveis: monocultivo (berinjela "solteira"); consórcio com Crotalaria juncea; e consórcio com Vigna unguiculata (feijão caupi).

Inicialmente, estabeleceram-se os tratamentos para adubação verde em pré-cultivo à cultura da berinjela. A semeadura do milheto e da crotalária foi feita em parcelas de $6 \times 5 \mathrm{~m}$, com o espaçamento de $30 \mathrm{~cm}$ entre linhas e uma densidade de 20 sementes por metro linear. As sementes da leguminosa receberam inóculos das estirpes de rizóbio selecionadas para a espécie, utilizando-se inoculantes produzidos na Embrapa Agrobiologia. As demais parcelas foram deixadas para crescimento da vegetação espontânea. O corte dos adubos verdes e da vegetação espontânea foi realizado 90 dias após a semeadura, quando iniciou o florescimento da crotalária. Imediatamente antes do corte dos pré-cultivos, avaliouse a fitomassa aérea, coletando-se aleatoriamente plantas de três fileiras de $3 \mathrm{~m}$ de cada parcela. Nas parcelas com vegetação espontânea foram utilizadas molduras de $0,5 \times 0,5 \mathrm{~m}$, distribuídas ao acaso, em quatro pontos de cada parcela para a quantificação da massa acumulada. Nestas parcelas, verificou-se abundância da 
leguminosa espontânea Indigofera hirsuta, misturada a diversas espécies de gramíneas, especialmente Panicum maximum (colonião), Cenchrus echinatus (capim-carrapicho), Eleusine indica (capim pé-de-galinha) e Cyperus rotundus (tiririca). A determinação da proporção da leguminosa I. hirsuta na vegetação espontânea foi realizada pela técnica de ${ }^{13} \mathrm{C}$ (Alves et al., 1999), pois era a única espécie de ciclo $C_{3}$ presente nas parcelas com vegetação espontânea. A análise isotópica foi feita na amostra da fitomassa total (mistura) e em amostras de plantas individualizadas da leguminosa e das gramíneas empregadas como referência de espécies $\mathrm{C}_{3}$ e $\mathrm{C}_{4}$, respectivamente.

Utilizou-se enxada rotativa para a incorporação da vegetação espontânea nas parcelas correspondentes ao tratamento de plantio convencional da berinjela. Nos demais, o material vegetal foi deixado sobre o solo, correspondendo aos tratamentos de plantio direto. No mesmo dia, foi realizado o transplantio de berinjela, no espaçamento de 1,40x0,70 m. Foram utilizadas plântulas com 5 a $7 \mathrm{~cm}$ de altura, desenvolvidas em bandejas contendo substrato orgânico. Em cada cova, o equivalente a $200 \mathrm{~kg} / \mathrm{ha}$ de $\mathrm{N}$ foi adicionado como esterco de curral curtido, com uma abundância natural de ${ }^{15} \mathrm{~N}$ de 7,1 deltas. A aplicação do esterco foi feita em todos os tratamentos para evitar que plantas deficientes em $\mathrm{N}$ proporcionassem condições para a entrada de doenças e pragas na área sob manejo orgânico. Além do esterco, foram adicionadas cerca de $250 \mathrm{~kg} / \mathrm{ha}$ de cinzas e $250 \mathrm{~kg} / \mathrm{ha}$ de farinha de osso, que juntos continham o equivalente a $5,5 \mathrm{~kg} / \mathrm{ha}$ de nitrogênio. Uma semana após o transplantio, foram semeadas nas entrelinhas da berinjela três linhas das leguminosas crotalária e caupi, na densidade de 30 sementes por metro linear. As leguminosas receberam inóculos de estirpes de rizóbio selecionadas para cada espécie, tal como mencionado anteriormente para crotalária.

O corte das leguminosas consorciadas foi realizado 50 dias após a semeadura, quando ambas estavam florescendo. $\mathrm{O}$ aporte de fitomassa das leguminosas foi avaliado amostrando-se três fileiras de $2 \mathrm{~m}$ para crotalária, e de $1 \mathrm{~m}$, para caupi. Os frutos de berinjela foram colhidos semanalmente, por um período de 18 semanas, a partir dos 50 dias do plantio, que coincidiu com o corte das leguminosas consorciadas. Foram considerados, para efeito de produtividade, frutos com menos de $20 \mathrm{~cm}$, adequados para comercialização em bandejas de isopor.
As amostras coletadas dos adubos verdes de précultivo e consórcio, e as amostras de frutos de berinjela, foram secadas em estufa com ventilação forçada à temperatura de $65^{\circ} \mathrm{C}$, até peso constante, para determinação da massa de matéria seca. $\mathrm{O}$ conteúdo total de $\mathrm{N}$ foi determinado por digestão sulfúrica, pelo método semimicro Kjeldahl (Alves et al., 1994). A quantidade de $\mathrm{N}$ acumulada pelas plantas foi calculada pelo produto da massa da matéria seca pelo conteúdo de nitrogênio. Para o cálculo da quantidade de $\mathrm{N}$ acumulada nos frutos de berinjela, utilizou-se a massa da matéria seca total de frutos comerciais e não comerciais.

Na determinação da contribuição da FBN para as leguminosas, utilizou-se a técnica de abundância natural de ${ }^{15} \mathrm{~N}$ (Shearer \& Kohl, 1986). Na ocasião dos cortes das leguminosas em pré-cultivo e consorciadas, espécies não leguminosas (não-fixadoras de $\mathrm{N}_{2}$ ) foram coletadas nas parcelas para serem utilizadas como testemunhas da marcação natural de ${ }^{15} \mathrm{~N}$ do solo/esterco. No cálculo da quantificação da FBN, considerou-se B (discriminação isotópica de ${ }^{15} \mathrm{~N}$ devido a $\mathrm{FBN}$ ) igual a -1,00 para todas as leguminosas, com base nos dados de Boddey et al. (2000).

Uma avaliação preliminar da abundância natural de ${ }^{15} \mathrm{~N}$ nos limbos foliares, pecíolos e frutos de plantas de berinjela, desenvolvidas sobre palhada de milheto no sistema não consorciado com leguminosas, não mostrou diferenças significativas entre os valores de delta ${ }^{15} \mathrm{~N}$ encontrados nas diferentes partes da planta

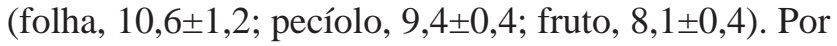
isso, a dinâmica da marcação de ${ }^{15} \mathrm{~N}$ nas folhas-índice (folhas recém-desenvolvidas) e frutos das plantas de berinjela foi acompanhada para verificar a utilização do $\mathrm{N}$ derivado dos resíduos das leguminosas de pré-cultivo e consórcio. As amostragens de folhas-índice ocorreram no dia do corte das leguminosas estabelecidas em consórcio, 15 e 40 dias após. As amostragens de frutos foram feitas aos 8 e 63 dias após o corte das leguminosas. Utilizou-se como referência da marcação natural de ${ }^{15} \mathrm{~N}$ do solo a cultura da berinjela sobre palhada de milheto (pré-cultivo), não consorciada. As folhas e frutos colhidos da berinjela, assim como plantas testemunhas, também foram secadas em estufa a $65^{\circ} \mathrm{C}$. Estes materiais e as amostras das espécies de pré-cultivo e consórcio foram moídos finamente e analisados quanto à abundância natural de ${ }^{15} \mathrm{~N}$ (Resende et al., 2003).

Realizou-se um balanço de N para o sistema, considerando-se a entrada de $\mathrm{N}$ pela FBN por adubos e a saída de $\mathrm{N}$ nos frutos da berinjela colhidos. Os dados 
foram submetidos à análise de variância em delineamento fatorial em blocos ao acaso, utilizando-se o programa estatístico MSTAT-C (Michigan State Univ.). As comparações das médias dos tratamentos foram feitas pelo teste Tukey, a 5\% de probabilidade. Comparações entre dados de abundância de ${ }^{15} \mathrm{~N}$ de testemunhas e milheto, e do milheto com esterco, foram feitas utilizando-se o teste t de Student.

\section{Resultados e Discussão}

A produção de matéria seca das plantas usadas na adubação verde e na cobertura do solo, antes do plantio da berinjela (pré-cultivo), variou de 4,5 a $6,5 \mathrm{Mg} / \mathrm{ha}$, o que representou um acúmulo de 51 a $126 \mathrm{~kg} / \mathrm{ha}$ de $\mathrm{N}$ (Tabela 1). A maior acumulação de $\mathrm{N}$ foi da crotalária, após um período de desenvolvimento de 90 dias. A abundância natural de ${ }^{15} \mathrm{~N}$ do milheto foi superior a das leguminosas (Tabela 1), porém não diferiu das espécies espontâneas $(6,05 \pm 0,30$ deltas $)$ presentes nas parcelas das leguminosas ( $\mathrm{P}>0,05$, teste $t$ de Student), e que refletiam a marcação do solo/esterco. A contribuição da FBN para a crotalária, determinada pela técnica de abundância natural de ${ }^{15} \mathrm{~N}$ foi próxima de $50 \%$ (Tabela 1), valor considerado baixo em comparação aos encontrados por Ramos et al. (2001) e Resende et al. (2003). A contínua aplicação de estercos para produção de hortaliças poderia estar proporcionando uma maior disponibilidade de $\mathrm{N}$ no solo, inibindo o processo da FBN na crotalária (Giller, 2001). Mesmo com uma baixa eficiência na FBN, a grande produção de fitomassa pela leguminosa proporcionou uma introdução de $\mathrm{N}$ no sistema derivado da FBN equivalente a $67 \mathrm{~kg} / \mathrm{ha}$ (Tabela 1), cerca de $50 \%$ da necessidade média de $\mathrm{N}$ para a cultura da berinjela (Haag \& Minami, 1988).
Nas parcelas em que diversas espécies cresceram espontaneamente, $59 \%$ da matéria seca acumulada era da leguminosa nativa Indigofera hirsuta, o que foi revelado pela técnica de abundância natural de ${ }^{13} \mathrm{C}$, e o restante, uma mistura de diversas espécies nãoleguminosas (Tabela 1). As condições de competição, principalmente com gramíneas, em que se encontrava esta leguminosa estimulou o sistema fixador de $\mathrm{N}_{2}$, e do total do $\mathrm{N}$ acumulado por todas as espécies presentes (leguminosas e não-leguminosas), cerca de $48 \mathrm{~kg} / \mathrm{ha}$ foram derivados da FBN, provavelmente associada, em grande parte, à $I$. hirsuta. Os dados de produção de fitomassa e acumulação de $\mathrm{N}$ pela vegetação espontânea foram considerados os mesmos nos tratamentos de plantio direto e convencional da berinjela, uma vez que antes do plantio da berinjela, as condições do solo eram as mesmas.

A adubação verde de pré-plantio com leguminosas somente influenciou a produção de frutos de berinjela e seu teor de $\mathrm{N}$ na terceira colheita, detectado nas parcelas de berinjela solteira (Tabela 2). Admitindo-se que as plantas de berinjela cresceram sob idênticas condições de solo fertilizado com esterco, a diluição isotópica observada só poderia ser explicada pela utilização de $\mathrm{N}$ derivado dos adubos verdes com leguminosas. Calculando-se a transferência de $\mathrm{N}$ para as plantas de berinjela, verificou-se, nesta amostragem, que 22,9, 20,6 e $23,5 \%$ do $\mathrm{N}$ seriam derivados da FBN para as plantas desenvolvidas, respectivamente, sobre a palha da crotalária, da vegetação espontânea (plantio direto) e no tratamento de plantio convencional da berinjela nas parcelas com vegetação incorporada (Tabela 2). Embora a quantidade de esterco adicionada fosse o equivalente a $200 \mathrm{~kg} / \mathrm{ha}$ de $\mathrm{N}$, infere-se que somente uma pequena fração tenha ficado disponível para as plantas até esta amostragem. Almeida (1991) mostrou que o esterco apresenta baixa eficiência relativa no fornecimento de N, sendo importante, todavia, como condicionador do solo e como uma reserva de nutrientes a médio prazo.

Tabela 1. Massa de matéria seca (MS), acumulação de N e contribuição da fixação biológica de nitrogênio (FBN) de plantas utilizadas como pré-cultivo. Valores médios de três repetições ${ }^{(1)}$.

\begin{tabular}{lcccccc}
\hline Pré-cultivo & $\begin{array}{c}\mathrm{MS} \\
(\mathrm{Mg} / \mathrm{ha})\end{array}$ & $\begin{array}{c}\mathrm{N} \text { total } \\
(\mathrm{kg} / \mathrm{ha})\end{array}$ & $\begin{array}{c}\text { Proporção de leguminosa } \\
(\% \mathrm{MS})\end{array}$ & $\begin{array}{c}\delta^{15} \mathrm{~N} \\
(\% \circ)\end{array}$ & $\begin{array}{c}\mathrm{FBN}^{(2)} \\
(\%)\end{array}$ & $\begin{array}{c}\mathrm{FBN} \\
(\mathrm{kg} / \mathrm{ha})\end{array}$ \\
\hline Milheto & $5,7 \mathrm{a}$ & $51 \mathrm{a}$ & 0 & $5,37 \mathrm{a}$ & 0 & 0 \\
Crotalária & $6,5 \mathrm{a}$ & $126 \mathrm{a}$ & 100 & $2,32 \mathrm{~b}$ & 53 & 67 \\
Vegetação espontânea & $4,5 \mathrm{a}$ & $83 \mathrm{a}$ & $59^{(3)}$ & $1,97 \mathrm{~b}$ & 57 & 48 \\
\hline CV $(\%)$ & 27,5 & 35,9 & - & 9,4 & - & - \\
\hline
\end{tabular}

${ }^{(1)}$ Médias seguidas pela mesma letra não diferem a $5 \%$ de probabilidade pelo teste de Tukey; a ausência de letras indica que não foram feitas comparações entre as médias. ${ }^{(2)} \mathrm{No}$ cálculo da porcentagem de $\mathrm{FBN}$ nas leguminosas, utilizou-se o valor de $\delta^{15} \mathrm{~N}$ da testemunha igual a $6,05 \pm 0,13$, obtido da média dos valores encontrados para as espécies espontâneas não-leguminosas que cresciam nas parcelas. ${ }^{(3)}$ Proporção da leguminosa nativa Indigofera hirsuta na matéria seca total da vegetação espontânea. 
Embora o desenvolvimento das leguminosas consorciadas com a berinjela tenha sido semelhante em toda a área experimental, a contribuição da FBN variou em razão dos tratamentos de adubação verde de pré-cultivo da berinjela (Tabela 3). No tratamento que se utilizou a crotalária em pré-cultivo, encontrou-se a menor contribuição da FBN para a crotalária e para o caupi plantados em consórcio com a berinjela, o que pode ser explicado pela inibição do processo de FBN por causa de um aumento do N disponível do solo (Giller, 2001), resultante da decomposição dos resíduos da crotalária usada como adubo verde. A contribuição da FBN para crotalária e caupi, quando estabelecidas em consórcio com a berinjela sobre os resíduos da vegetação espontânea foram semelhantes. A maior contribuição da FBN foi a do caupi crescido sobre resíduos de milheto. Em geral, maiores contribuições da FBN foram dadas pelo caupi, o que repercutiu em maiores quantidades de $\mathrm{N}$ introduzidas no sistema chegando a $68 \mathrm{~kg} / \mathrm{ha}$ quando o pré-cultivo foi milheto (Tabela 3 ).

A análise das duas primeiras coletas da folha-índice não mostrou diferenças entre os tratamentos, quanto à marcação natural das plantas de berinjela com ${ }^{15} \mathrm{~N}$ (Figura 1). Na terceira coleta, em praticamente todos os tratamentos, observou-se uma diluição da marcação

Tabela 2. Matéria seca, teor de $\mathrm{Ne}$ abundância natural de ${ }^{15} \mathrm{~N}$ dos frutos da berinjela não consorciada, obtidos na terceira amostragem, aos 60 dias após transplantio, e estimativa da proporção do $\mathrm{N}$ dos frutos derivado da FBN nos pré-cultivos. Valores médios de três repetições ${ }^{(1)}$.

\begin{tabular}{lcccc}
\hline Pré-cultivo & $\begin{array}{c}\text { Matéria seca } \\
(\mathrm{kg} / \mathrm{ha})\end{array}$ & $\begin{array}{c}\text { Teor de N } \\
(\mathrm{g} / \mathrm{kg})\end{array}$ & $\begin{array}{l}\delta^{15} \mathrm{~N} \\
(\%)\end{array}$ & $\begin{array}{c}\text { Transferência } \\
\text { de N }(\%)\end{array}$ \\
\hline Milheto & $93,7 \mathrm{ab}$ & $19,6 \mathrm{~b}$ & $7,12 \mathrm{a}$ & 0,0 \\
Crotalária & $120,3 \mathrm{a}$ & $32,4 \mathrm{a}$ & $5,49 \mathrm{~b}$ & 22,9 \\
Vegetação espontânea & $136,8 \mathrm{a}$ & $30,0 \mathrm{a}$ & $5,65 \mathrm{~b}$ & 20,6 \\
Vegetação espontânea - incorporada & $74,4 \mathrm{~b}$ & $14,9 \mathrm{~b}$ & $5,45 \mathrm{~b}$ & 23,5 \\
\hline CV $(\%)$ & 18,1 & 16,2 & 10,2 & - \\
\hline
\end{tabular}

(1)Médias seguidas pela mesma letra não diferem a $5 \%$ de probabilidade pelo teste de Tukey; a ausência de letras indica que não foram feitas comparações entre as médias.

Tabela 3. Fixação biológica de nitrogênio nos adubos verdes, crotalária e caupi, consorciados com berinjela, após diferentes pré-cultivos. Valores médios de três repetições ${ }^{(1)}$.

\begin{tabular}{lccccc}
\hline Pré-cultivo & \multicolumn{2}{c}{$\%$ FBN } & & \multicolumn{2}{c}{ FBN $(\mathrm{kg} / \mathrm{ha})$} \\
\cline { 2 - 3 } \cline { 6 - 6 } & Crotalária & Caupi & & Crotalária & Caupi \\
\hline Milheto & $57,3 \mathrm{ab}$ & $91,9 \mathrm{a}$ & & $22,9 \mathrm{bc}$ & $68,0 \mathrm{a}$ \\
Crotalária & $20,8 \mathrm{~d}$ & $40,5 \mathrm{~cd}$ & $8,3 \mathrm{c}$ & $29,9 \mathrm{abc}$ \\
Vegetação espontânea & $79,1 \mathrm{ab}$ & $76,3 \mathrm{ab}$ & & $31,6 \mathrm{abc}$ & $56,5 \mathrm{ab}$ \\
Vegetação espontânea - incorporada & $85,9 \mathrm{ab}$ & $81,5 \mathrm{ab}$ & $34,4 \mathrm{abc}$ & $60,3 \mathrm{ab}$ \\
\hline Média & $60,8 \mathrm{~A}$ & $72,6 \mathrm{~B}$ & & $24,3 \mathrm{~A}$ & $53,7 \mathrm{~B}$ \\
CV $(\%)$ & \multicolumn{3}{c}{16,2} & & \multicolumn{2}{c}{35,8} \\
\hline
\end{tabular}

(1)Médias seguidas pela mesma letra, minúscula na coluna e maiúscula na linha, não diferem a $5 \%$ de probabilidade pelo teste de Tukey. natural de ${ }^{15} \mathrm{~N}, 30$ dias após o corte do consórcio. Embora seja difícil separar os efeitos de pré-cultivo e consórcio, os resultados sugerem uma transferência de $\mathrm{N}$ derivado da FBN associado às leguminosas utilizadas em consórcio, uma vez que também foi observado nos tratamentos que a berinjela consorciada cresceu sobre a palhada de milheto usado como adubo verde de précultivo (Figuras 1 e 2). A avaliação da abundância natural de ${ }^{15} \mathrm{~N}$ nos frutos indica que os efeitos de adubação

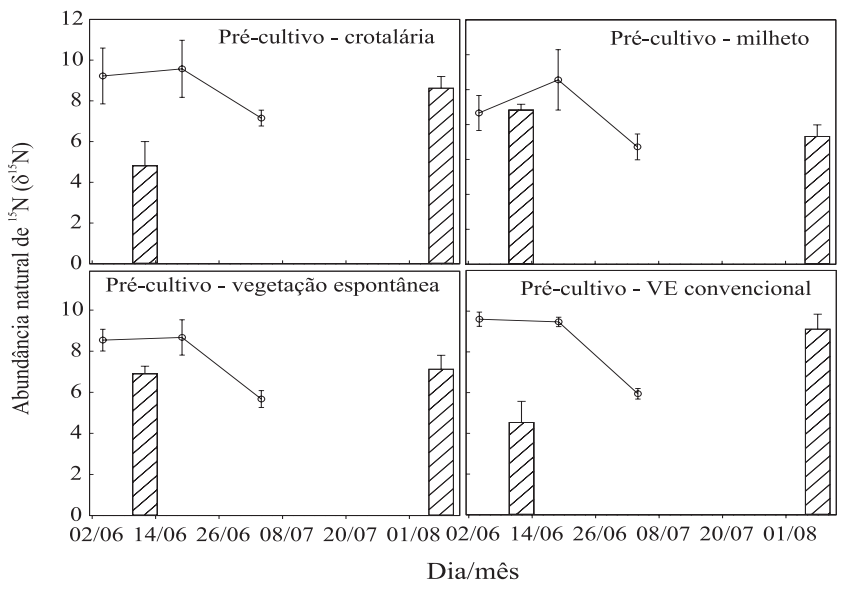

Figura 1. Valores da abundância natural de ${ }^{15} \mathrm{~N}$ de folhasíndice $(\rightarrow-)$ de berinjela, consorciada com crotalária, após diferentes pré-cultivos, coletadas em três épocas ( $04 / 06$ - corte do consórcio, 19/06 e 04/07) e de frutos $(\square ; 12 / 06$ - terceira colheita e 07/08 - décima primeira colheita). As barras nos pontos e nas colunas representam o erro padrão da média.

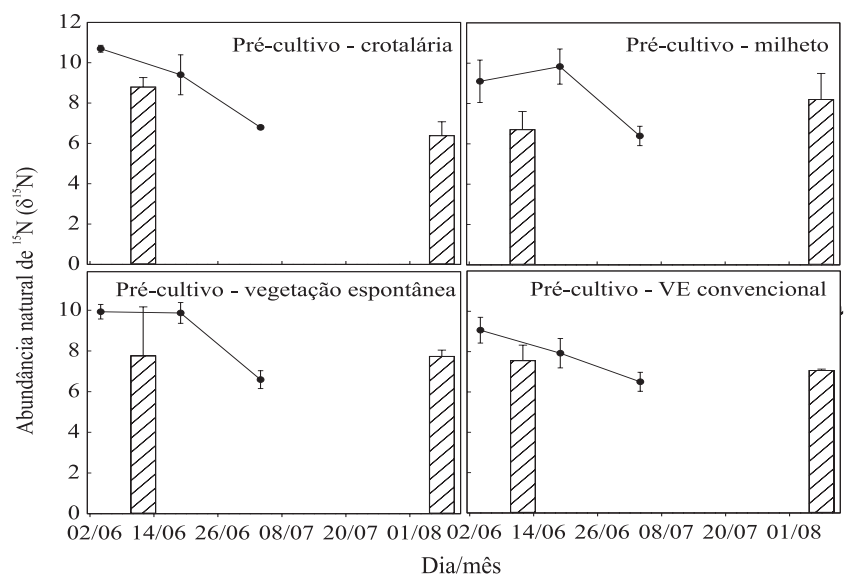

Figura 2. Valores da abundância natural de ${ }^{15} \mathrm{~N}$ de folhas-índice $(-$-) de berinjela, consorciada com caupi, após diferentes pré-cultivos, coletadas em três épocas (04/06 corte do consórcio, 19/06 e 04/07) e de frutos $(\square ; 12 / 06$ terceira colheita e 07/08 - décima primeira colheita). As barras nos pontos e nas colunas representam o erro padrão da média. 
verde praticamente desapareceram na 11 a colheita (57 dias após a primeira colheita), quando os valores de delta ${ }^{15} \mathrm{~N}$ não foram diferentes do encontrado no solo/esterco ( $\mathrm{P}>0,05$, teste $\mathrm{t}$ de Student).

A produtividade da berinjela, após 18 colheitas consecutivas, foi próxima da média nacional de $25 \mathrm{Mg} / \mathrm{ha}$ (Ribeiro et al., 1998), não sofrendo efeito significativo dos tratamentos de adubação verde de pré-cultivo e consórcio (Tabela 4). Hödtke et al. (1999), em experimento realizado na mesma área, porém com milho consorciado com caupi (duas linhas entre plantas de milho), cortados e deixados na superfície do solo, também não encontraram diferenças de produtividade quanto ao manejo adotado. No entanto, pela avaliação das folhas-índice de milho, coletadas sete dias após o corte do

Tabela 4. Produtividade de frutos comerciais de berinjela (comprimento inferior a $20 \mathrm{~cm}$ ), em monocultura (solteira) e consorciada com crotalária ou caupi, após diferentes pré-cultivos. Médias de três repetições ${ }^{(1)}$.

\begin{tabular}{lccc}
\hline Pré-cultivo & Solteira & \multicolumn{2}{c}{ Consórcio } \\
\cline { 3 - 4 } & & Crotalária & Caupi \\
\hline Milheto & $15,2 \mathrm{a}$ & $22,2 \mathrm{a}$ & $23,9 \mathrm{a}$ \\
Crotalária & $23,5 \mathrm{a}$ & $22,7 \mathrm{a}$ & $19,5 \mathrm{a}$ \\
Vegetação espontânea & $26,9 \mathrm{a}$ & $21,6 \mathrm{a}$ & $18,9 \mathrm{a}$ \\
Vegetação espontânea - incorporada & $20,4 \mathrm{a}$ & $16,7 \mathrm{a}$ & $18,1 \mathrm{a}$ \\
\hline Média & $21,5 \mathrm{~A}$ & $20,8 \mathrm{~A}$ & $20,1 \mathrm{~A}$ \\
\hline (1) Médias seguidas pela mesma letra, minúscula na coluna e maiúscula na \\
linha, não diferem a 5\% de probabilidade pelo teste de Tukey; o coefi- \\
ciente de variação foi de 31,1\%.
\end{tabular}

consórcio, detectou-se um aumento no teor de $\mathrm{N}$ nas folhas, indicando que aplicação de $\mathrm{N}$ via adubo verde ficou rapidamente disponível para a cultura do milho, situação semelhante à encontrada neste estudo.

Apesar da dificuldade em se estimar a quantidade de $\mathrm{N}$ derivada dos adubos verdes utilizada pela cultura da berinjela, as variações na abundância natural de ${ }^{15} \mathrm{~N}$ nos frutos e folhas indicam que a adubação verde, em précultivo e consórcio, foi importante no fornecimento de $\mathrm{N}$ para esta cultura. No entanto, considerando-se o sistema solo-planta, a presença das leguminosas significou a introdução de $\mathrm{N}$ derivado da FBN, que seria suficiente para balancear as exportações de $\mathrm{N}$ pelos frutos da berinjela (Tabela 5). A produtividade de frutos de berinjela resultou numa exportação de 40,0 a 70,8 $\mathrm{kg} \mathrm{ha}^{-1}$ de $\mathrm{N}$ e a utilização de leguminosas, uma adição de $\mathrm{N}$ via FBN que variou de 23 a $104 \mathrm{~kg} \mathrm{ha}^{-1}$.

O resultado do balanço parcial de $\mathrm{N}$ para os pré-cultivos, considerando somente a entrada de $\mathrm{N}$ pela FBN (balanço parcial), foi negativo em todos os tratamentos exceto no pré-cultivo com crotalária, por causa da grande biomassa acumulada em 90 dias (Tabela 5). A quantidade de $\mathrm{N}$ fornecida ao sistema pela vegetação espontânea, via FBN, não foi suficiente para garantir um balanço positivo de nitrogênio. A utilização do sistema misto, com adubação verde com leguminosas de pré-cultivo e consórcio, resultou em um balanço par-

Tabela 5. Quantidade de N derivada da FBN introduzida no sistema de produção de berinjela pela adubação verde de précultivo e consórcio, quantidade de $\mathrm{N}$ exportada nos frutos de berinjela (saída), e balanço de $\mathrm{N}$ para o solo calculado pela diferença entre a contribuição da FBN e a exportação de N nos frutos (balanço parcial) ou a diferença entre a entrada pela FBN e insumos orgânicos ${ }^{(1)}$ e a exportação de $\mathrm{N}$ nos frutos (balanço total).

\begin{tabular}{lcccc}
\hline Pré-cultivos & Contribuição da FBN & Saída $(2)$ & Balanço parcial & Balanço total \\
\hline Milheto & 0,0 & 48,0 & $-48,0$ & $+157,5$ \\
Crotalária & 67,0 & 59,6 & $+7,4$ & $+212,9$ \\
Vegetação espontânea & 48,0 & 70,8 & $-22,8$ & $+182,7$ \\
Vegetação espontânea - incorporada & 48,0 & 55,2 & & \\
Pré-cultivo/leguminosa em consórcio & & & & \\
Milheto/crotalária & $22,9(0+22,9)$ & 58,8 & $-35,9$ & $+169,3$ \\
Milheto/caupi & $68,0(0+68,0)$ & 61,8 & $+6,2$ & $+211,7$ \\
Crotalária/crotalária & $75,3(67,0+8,3)$ & 59,7 & $+15,6$ & $+221,1$ \\
Crotalária/caupi & $96,6(67,0+29,6)$ & 51,8 & $+44,8$ & $+250,3$ \\
Vegetação espontânea/crotalária & $79,6(48,0+31,6)$ & 53,1 & $+26,6$ & $+232,1$ \\
Vegetação espontânea/caupi & $104,5(48,0+56,5)$ & 51,8 & $+52,7$ & $+258,2$ \\
Vegetação espontânea - incorporada/crotalária & $82,4(48,0+34,4)$ & 47,0 & $+35,4$ & $+240,9$ \\
Vegetação espontânea - incorporada/caupi & $108,3(48,0+60,3)$ & 47,5 & $+60,9$ & $+266,4$ \\
\hline
\end{tabular}

${ }^{(1)}$ A quantidade de $\mathrm{N}$ em insumos orgânicos foi de $205,5 \mathrm{~kg} / \mathrm{ha}$. ${ }^{(2)}$ Valores de extração de $\mathrm{N}$ computados na produtividade total, inclusive nos frutos não comerciais (utilizou-se um valor médio de porcentagem de matéria seca de frutos de $9 \%$, com 1,97\% de $\mathrm{N}$ ). 
cial sempre positivo devido à maior entrada de $\mathrm{N}$ derivado da fixação biológica do nitrogênio.

Um balanço de $\mathrm{N}$, em que se incluem as quantidades de $\mathrm{N}$ introduzidas pelo esterco e outros insumos, mostra um grande excedente de $\mathrm{N}$ no solo sujeito a perdas para o ambiente (Tabela 5).

\section{Conclusões}

1. O uso de leguminosas na adubação verde em précultivo e consórcio contribui significativamente para o fornecimento de $\mathrm{N}$ para a cultura da berinjela.

2. A quantidade de $\mathrm{N}$ introduzida pela fixação biológica derivada da adubação verde de pré-cultivo e consórcio com berinjela é suficiente para compensar o $\mathrm{N}$ exportado pela colheita de frutos.

\section{Referências}

ALMEIDA, D.L. de. Contribuição da adubação orgânica para a fertilidade do solo. 1991. 192p. Tese (Doutorado) - Universidade Federal Rural do Rio de Janeiro, Seropédica.

ALVES, B.J.R.; OLIVEIRA, O.C.; URQUIAGA, S.; BODDEY, R.M. Métodos isotópicos. In: SANTOS, G.A.; CAMARGO, F.A.O. (Org.). Fundamentos da matéria orgânica do solo: ecossistemas tropicais e subtropicais. Porto Alegre: Genesis, 1999. p.337-357.

ALVES, B.J.R.; SANTOS, J.C.F.; URQUIAGA, S.; BODDEY, R.M Métodos de determinação do nitrogênio em solo e planta. In: HUNGRIA, M.; ARAÚJO, R.S. (Org.). Manual de métodos empregados em estudos de microbiologia agrícola. Brasília: Embrapa-SPI, 1994. p.449-469.

BODDEY, R.M.; PEOPLES, M.B.; PALMER, B.; DART, P.J. Use of the ${ }^{15} \mathrm{~N}$ natural abundance technique to quantify biological nitrogen fixation by woody perennials. Nutrient Cycling in Agroecosystems, v.57, p.235-270, 2000.

BRASIL. Ministério da Agricultura e do Abastecimento. Instrução Normativa n. 007, de 17 de maio de 1999. Dispõe sobre normas para a produção de produtos orgânicos vegetais e animais. Diário Oficial [da] República Federativa do Brasil, Brasília, 19 maio 1999. Seção 1, p.11-14, 1999.

CALEGARI, A. Coberturas verdes em sistemas intensivos de produção. In: WORKSHOP NITROGÊNIO NA SUSTENTABILIDADE DE
SISTEMAS INTENSIVOS DE PRODUÇÃOAGROPECUÁRIA, 2000, Dourados. Anais. Dourados: Embrapa Agropecuária Oeste; Embrapa Agrobiologia, 2000. p.141-153.

EMBRAPA. Centro Nacional de Pesquisa de Solos (Rio de Janeiro, RJ). Manual de métodos de análise de solos. Rio de Janeiro, 1997. 212p.

FILGUEIRA, F.A.R. Novo manual de olericultura: agrotecnologia moderna na produção e comercialização de hortaliças. Viçosa: UFV, Imprensa Universitária, 2000. 402p.

GILLER, K.E. Nitrogen fixation in tropical cropping systems. 2nd ed. Wallingford: CAB International, 2001. 448p.

HAAG, H.P.; MINAMI, K. Nutrição mineral em hortaliças. 2.ed. Campinas: Fundação Cargill, 1988. 538p.

HÖDTKE, M.; ARAÚJO, P.A.; KÖPKE, U.; ALMEIDA, D.L. Nutritional status, grain yield and N-balance of organically grown maize intercropped with green manure. In: FOGUELMAN, D.; LOCKERETZ, W. (Ed.). Organic agriculture: the credible solution for the XXIst century. Mar del Plata: International Federation of Organic Agriculture Moviment, 1999. p.135-141.

RAMOS, M.G.; VILLATORO, M.A.A.; URQUIAGA, S.; ALVES, B.J.R.; BODDEY, R.M. Quantification of the contribution of biological nitrogen fixation to tropical green manure crops and the residual benefit to a subsequent maize crop using ${ }^{15} \mathrm{~N}$-isotope techniques. Journal of Biotechnology, v.91, p.105-115, 2001.

RESENDE, A.S. de; XAVIER, R.P.; QUESADA, D.M.; URQUIAGA, S.; ALVES, B.J.R.; BODDEY, R.M. Use of green manures in increasing inputs of biologically fixed nitrogen to sugar cane. Biology and Fertility of Soils, v.37, p.215-220, 2003.

RIBEIRO, C.S.C. da; BRUNE, S.; REIFSCHNEIDER, F.J.B. Cultivo da berinjela (Solanum melongena L.). Brasília: Embrapa Hortaliças, 1998. 23p. (Instruções Técnicas, 15).

SÉGUY, L.; BOUZINAC, S.; TRENTINI, A.; CORTES, N. de A. Gestão da fertilidade de culturas mecanizadas nos trópicos úmidos: o caso das frentes pioneiras nos cerrados e florestas úmidas no centro norte do Mato Grosso. In: PEIXOTO, R.T. dos G.; AHRENS, D.C.; SAMAHA, M.J. (Ed.). Plantio direto: o caminho para uma agricultura sustentável. Ponta Grossa: Iapar, 1997. p.124-157.

SHEARER, G.; KOHL, D.H. $\mathrm{N}_{2}$-fixation in field settings: estimations based on natural ${ }^{15} \mathrm{~N}$ abundance. Australian Journal of Plant Physiology, v.13, p.699-756, 1986.

TRANI, P.E.; RAIJ, B. van. Hortaliças. In: RAIJ, B. van; CANTARELLA, H.; QUAGGIO, J.A.; FURLANI, A.M.C. (Ed.). Recomendações de adubação e calagem para o Estado de São Paulo. 2.ed. Campinas: Instituto Agronômico \& Fundação IAC, 1996. p.155-185.

Recebido em 12 de novembro de 2003 e aprovado em 8 de junho de 2004 